\title{
Mobile Selves: Gender, ethnicity and mobile phones in the everyday lives of young Pakistani-British women and men
}

\section{Eileen Green and Carrie Singleton}

\begin{abstract}
This paper focuses upon mobile phone use by a young minority ethnic group as a medium through which to explore diversity and technology use in everyday life. Recent research with young people has shown that mobile phones are instrumentally, socially and emotionally important but few have problematised the homogeneous concept of 'youth'. This paper argues for increased recognition of the intersections of social categories such as youth, gender and ethnicity with technologies, specifically mobile phones, in order to understand complexity of use. Drawing upon new empirical, qualitative data from an urban area in the North East of England we explore the focus group narratives of young Pakistani-British Muslim women and men focusing on the notion of 'shifting' gendered and cultural identities and social practices, developed and reworked in relation to the use of mobile phones. We look at the gendered dynamics of mobile use, including gender talk and text, and ask whether the young women and men experience mobiles differently in everyday life. We also explore the ways in which mobiles are used to create 'space of one's own' and the gendered dynamics of remaining connected, especially to key peer groups. The paper concludes with the assertion that in order to fully explore the mutability of youth cultures across space and time, we need to develop a more dynamic concept of 'mobile selves' by exploring the place and meaning of technologies such as mobile phones in the rich tapestries of young people's lives.
\end{abstract}

\section{Key words}

Mobile phones; gender; ethnicity; culture; identity; technology 


\section{Introduction}

Statistics show that in $2003,88 \%$ of the UK population aged 15 to 24 owned mobile phones (ONS 2003) and this figure continues to rise. Recent research with under 25's suggests that mobile phones are instrumentally, socially and emotionally important (Green 2003). They are used for keeping in touch with family and friends, ensuring personal safety, co-ordinating social and peer group activities, forging and sustaining intimate relationships, 'digital gift giving', and ritual exchanges (Ling 2000; Harper 2003). While there is increasing academic interest in this area, the intersections of social categories such as age, gender, ethnicity, social class, and faith with information and communication technologies (ICTs), in particular, mobile phones, in young people's lives remain under explored. Although many have pointed to the mobile phones 'phenomenon' amongst young people, few studies have problematised the homogeneous concept of 'youth'. Green (2003: 201) argues that we need explorations of multiple and diverse configurations of identity and social relationships which challenge one dimensional associations between 'youth' and technologies, emphasising the multiplicity of economic, cultural and social values attributed to mobile phones by different groups of young people. Similarly, authors within feminist science and technology studies echo the need to critically analyse diversity and difference (Kennedy 2005). This paper argues for recognition of the intersections of social categories such as youth, gender and ethnicity with technologies, specifically mobile phones, in order to gain a better understanding of the ways in which different individuals interact with technologies in everyday life.

In recent years, theorists drawing upon postmodern concepts have challenged the monolithic and sometimes stereotypical representations of youth found in some subcultural approaches (for a useful overview see Nayak 2003). They contend that 
studies of youth cultures need to take account of the changing nature of youth subjectivities over time and across space. This work also demonstrates how young people move in and out of particular groupings and identifications and draw upon a wide range of local and global cultural references. Youth groups are not, therefore, homogeneous or static entities. Instead, young people are involved in complex relationships and interactions with peers, family, institutions, spaces / places and technologies, all of which influence the shaping of social identities. In order to fully explore the mutability of youth cultures across space and time, we argue for the need to examine the more dynamic concept of plural 'identities' and what shapes them. This paper interrogates the concept of 'mobile selves' focusing in particular upon how mobile phones have become an integral part of young people's sense of self and in turn how different groups of young people appropriate these new technologies and shape them to their own needs and uses. We argue that investigating their choice and personalisation of mobiles, together with diversity of use, reveals multi-faceted, fluid concepts of self. Drawing upon new qualitative data from a research project based in the North East of England we explore the focus group narratives of young $(15-25$ years $)$ Pakistani-British Muslims ${ }^{\mathrm{ii}}$ focusing on the notion of 'shifting' and intersecting gendered and cultural identities and social practices, developed and reworked in relation to the use of mobile phones. Examining the gendered dynamics of mobile phone use, we ask whether young women and men experience mobiles differently in everyday life. We also explore mobiles as spaces of belonging and connectivity to family and friends across global and local networks and the processes by which young women and men identify with and appropriate different styles of phones and phone practices. Consideration is also given to the ways in which mobiles are used to create virtual and private 'spaces of their own'. 


\section{Mobile phones, 'difference' and the performance of youth identities in everyday life}

A rapidly expanding area of mobile phone research has centred upon youth populations (children, teenagers and young adults) who form the largest active user group of this type of technology and its accessories on a global scale. The attraction of mobiles has been linked to their spatial and time adjusting capabilities, with young people citing advantages such as calling on the move, texting at any time of the day and night and continuous access to entertainment, such as games and information, via the internet (cf Ling 2004; Green 2003). This research has yielded some interesting findings, but tends to draw upon, for example, large scale survey results, white European youth populations and young people situated within national contexts. There has been less of a focus upon the intricate and complex processes of adoption and use amongst diverse youth cultures. In an effort to flesh out perspectives which can accommodate the impact of diversity, we conducted empirical research which enabled us to explore differences of gender, ethnicity and age upon the meaning and use of mobiles.

Our analysis synthesises two bodies of feminist work to enable an enhanced understanding of gender, identity and mobile phone use. Feminist theories of technology underscore the mutually shaping relationship between gender and technology where technologies are viewed as both a source and a consequence of gender relations (Wajcman 2004; Faulkner 2001; Green and Adam 2001). The 'social shaping' thesis links with earlier work on communication technologies that posits the telephone as a feminised and domesticated technology, subverting the traditional association of masculinity with technologies which forms a useful foundation for studies of gender, diversity and the mobile phone (Lohan 2001). The concept of technologies as gendered is 
further strengthened by more recent research on gender and mobile phones that explores the concept of 'remote mothering', where the mobile is seen to facilitate an extension of the traditional gender division of labour away from the home (Rakow and Navarro 1993; Wajcman 2004). This resonates with earlier research which found that females use the telephone more for communication with family and friends than work (Rakow 1988) and that the phone is a crucial part of girls' and women's socialising and support structures (Moyal 1992; Frissen 1995). The mobile has been appropriated by women of all ages for social purposes and for personal safety (Wajcman 2004), although there may also be differences in terms of access to mobiles, the conditions under which access is permitted and actual use (Terry and Calvert 1997). Research carried out in Israel suggests that whilst the mobile may be 'blurring' some gender differences, by encouraging men to talk more and women to use such innovative technologies, it still constitutes a 'site' where gender identities are performed (Lemish and Cohen 2005). However, the relationship between the performance of femininities and masculinities and mobile phone behaviour remains under explored. We argue that the mobile phone is an interesting site through which to explore gender relations and symbolic associations between technology and masculinity, raising questions about whether mobile phones can reconfigure, or fragment normative gender assumptions about men and technologies.

In spite of documented differences of attitude towards technology between males and females, less critical attention has been paid to the intersections of social differences, such as 'race' and ethnicity, on technology use and meanings. The body of work on 'difference' and the intersections of ethnicity, class, gender, sexuality and age can inform our understanding of the relationship between youth identities and mobile technologies

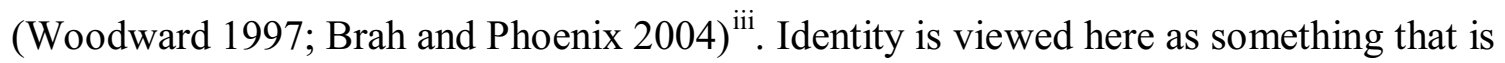
'in process', unfinished, constructed and reconstructed (Hall 1996), experienced, 
negotiated and contested in and through the ways people talk about and represent themselves / others and interact within social settings. Critical analysis of modes of 'commonality' and 'difference' enables us to capture different and shared aspects of social and cultural experience, and the feminist concept of intersectionality is useful here in explaining the interplay of categories of identity in young people's lives (Brah and Phoenix 2004). Peer groups are not homogenised, impermeable entities but a porous 'collection of individual lives, choices and experiences' (Alexander 1996: 18). We contend that young people are cultural innovators and consumers involved in a complex interface with ICTs that can effect social transformations.

\section{Methodology}

This paper draws upon findings from a qualitative pilot study of mobile phone use and its meanings for young minority ethnic women and men. Research participants were recruited from a town in the North East of England between December 2004 and April 2005. Discussion focuses upon six women's and three men's focus groups involving 47 participants aged between 14 and 25 years ( 29 women and 18 men). All participants were born in the UK and self-identified as Pakistani, Pakistani-British, and Asian-British. On occasion, they referred to themselves collectively as 'Asian' men and women, reflecting debates around internal and external definitions of ethnicity and different subject positions that individuals adopt (Alexander 1996). One of the focus groups consisted of young mothers who met at a local community centre to offer support and friendship.

The town's largest and long-established minority ethnic community is of Pakistani heritage and Muslim faith background. There are different Muslim communities residing in differing geographical areas, some of which experience higher levels of deprivation 
than others. Key informants also highlighted the existence of varied community groupings with differing interpretations of faith and culture, and this is reflected in the sample, enabling us to explore the specificities of local ethnicities and cultures (Back 1996). Participants are mostly third generation, and are currently in full-time education, look after family and children, in employment or are seeking work. The focus group method was adopted to enable participants to reflect, comment on and generate ideas about their use and perceptions of mobile phones in an interactive and dynamic group setting (Gibbs 1997). The data was analysed for emergent themes and group interaction and co-construction of meaning.

All but two of the younger women owned one or more mobile phones. Two 15 year olds were involuntary non-users, in the sense that they wanted mobile phones of their own but were not permitted by parents until they were older. They did, however, have access to older sibling's phones, demonstrating that the use / non-use dichotomy is inadequate for capturing the complexities surrounding use of and access to technologies. Respondents were accessed through 'community assistants', (two female and one male) key informants residing in the local communities who provided advice on cultural and gender sensitive aspects of the research, found appropriate venues, sought parental consent where necessary and encouraged participants to attend the focus groups. Although the majority of participants are bi or multi - lingual, interviews were conducted in English because respondents indicated this preference ${ }^{\mathrm{iv}}$. We employed a young Pakistani British man to conduct the male focus groups, to facilitate a close rapport and explore the intersections between ethnicity, masculinity and mobile use. 


\section{From local to global: Networked spaces of belonging and connectivity}

Use of a mobile phone was ubiquitous amongst our participants. Even the two female non-owners accessed opportunities to talk and text on mobiles belonging to older siblings and we did not encounter any 'rejecters' or mobile 'drop outs' within the sample. Like many other young people, our respondents carried and utilised mobiles everywhere and at all times: in the home, in public spaces, in school, college and university, at work and at leisure and whilst travelling; during the day and for some during the night. They were used mainly for voice calls for varied lengths of time and to text message, including most recently for picture and video messaging. Mobiles are used by participants to coordinate their everyday lives, including arranging places and times to meet and are also used expressively to communicate an array of social and emotional meanings.

The main reason given by all participants for owning a mobile phone was to enable them to be 'connected' to others. For the young mothers, this was particularly pertinent in terms of keeping in touch with relatives who were looking after their babies and young children, mirroring the research on 'remote mothering' discussed above. Whereas early mobile phones were considered by participants to be little more than fashionable gizmos, our data confirms that they now view mobiles as indispensable components of everyday life, reflecting the process of the 'domestication' of technologies theorised by Silverstone and Haddon (1996). In this focus group their discussion centred upon how they would feel if they no longer had access to mobile phones.

Interviewer: Can you imagine life without your mobile?

All group: No.

Irfan: $\quad$ There'd be no life.

(Group laughter)

Irfan: $\quad$ No seriously there wouldn't, its communication. 
Tahir: If tomorrow all the phones were taken back I'd be committing suicide. (Group laughter)

Naeem: $\quad$ You don't feel complete without mobile phones.

Irfan: $\quad$ No you don't.

Naeem: $\quad$ I'm used to carrying my needs around.

Tahir: $\quad$ That is true, it's true.

Naeem: $\quad$ But if I leave the house... I'll make sure that I've got a mobile phone, if I'm in [place name] and I haven't got my mobile phone - I live like ten minutes away [and I'll go and get it].

Tahir: $\quad$ I can forget my door key but I won't forget my phone.

The data here suggests that it is the mobile's multi-functionality and the comprehensiveness of it's capabilities that is important to these men. A mobile holds a large amount of important personal information in one place, making its absence acutely felt. In addition, the extract above reflects our finding that the majority of our sample gained a sense of security from continuous connection to their networks of support and belonging. One of the key expressions from both women and men that resonated throughout our research was 'keeping in touch', a turn of phrase used to describe their continuous connectivity to the social networks of family and friends that this device affords.

Theorists have commented on the mobile's capacity to offer 'perpetual contact' across globally situated networks (Katz and Aakhus 2002). The mobile and its use in everyday life alters our perceptions and conceptions of space and place, distance and presence and time, linking spatially detached individuals instantaneously (Urry 2000). Like other diasporic communities, the extent of the participants' social networks ranged from local ties through to national and global communities. Participants' relatives and friends were located in the local communities, in other UK towns and cities and in Pakistan. Mobile phones, amongst other technologies including the telephone and the internet enabled them to keep in touch with people across these networks, thereby maintaining both localised and more remote relationships, as the following group dialogue shows: 
Interviewer: Ok, so who do you call the most?

Amar: $\quad$ Everyone.

Adil: $\quad$ My friends.

Abbas: $\quad$ Family, friends, people abroad, all sorts.

Interviewer: People abroad, who like?

Abbas: $\quad$ Family innit.

Interviewer: What you call them abroad, don't you use the [phone] cards or anything like that?

Abbas: $\quad$ No, no you don't need that...

Khaliq: $\quad$ I've got friends all over England innit so, just phone up and see what's happening, make sure they're all chillin... everything's all right.

Participants talked about contacting relatives in Pakistan through via their mobiles but most often this was done through texting because of its inexpensiveness, as Sameena highlighted:

It's like an international thing as well isn't it ...like if you're sending them abroad then its maybes cheaper to send a message than ring.

For long voice conversations abroad most participants used the landline in the home for similar reasons of economy. One women's group also said that the areas where their family live in Pakistan did not yet receive good reception so they tended to use a landline instead. Some of the women reflected upon the error of making international calls on mobiles without realising the cost they would incur. For these young people, affordably keeping in touch with a network of friends and relatives across local and global spaces requires complex usage and a command of different technologies and services. As the narratives show, the desire to keep in touch overlaps with an individual's financial capability and technical knowledge, with young people finding and developing new strategies to maintain contact. 
Mobiles were also taken on visits to Pakistan by both men and women enabling them to keep in touch with UK contacts whilst away and to reap inflated profits through selling on. Some of the participants talked about buying cheap sim cards in Pakistan including taking advantage of the reduced cost of calls, as this men's group illustrates:

Interviewer: Right do you all take your phones with you [to Pakistan]?

Abbas: $\quad$ Definitely man, then sell them on, you get even more money... you make a lot more money that you would here.

Interviewer: So when's the last time you went?

Abbas: $\quad$ It was about two year[s] ago.

Waseem: $\quad$ Same here.

Interviewer: Did you take your mobile?

Abbas: Yeah.

Interviewer: Did you use it?

Abbas: $\quad$ Yeah, loads of times... Got a sim card from there [Pakistan] and banged it in and got a new number and that, making calls to everyone round here [in England], not really texting, calls.

Interviewer: So how much was it costing yer?

Abbas: It's like I wasn't paying for it mate so it didn't really matter.

Jameel: $\quad$ One of my boys took a phone from here [to Pakistan], Vodaphone. He had five pound credit on it. He phoned me, checked his balance, he had five pounds still. So he took advantage of it, he started phoning everybody; he had the five pound for about two month.

The data here suggests that a lack of co-ordination between network providers in different countries enabled possibly illicit use of mobile phones. Although there is insufficient data to corroborate this, the research also found that both the young men and women engaged in a thriving informal economy in mobile phones in their neighbourhoods in the UK. This also suggests that there is a complex informal economy of mobile communications and phone exchanges that operates across transnational spaces.

Entry to this networked space appears to be crucial for young people in terms of their inclusion in and belonging to localised peer groups, the wider community and to globally dispersed family groups, all forming an important part of a young person's social and 
cultural identity. Peer group involvement is vital to the shaping of identity and mobile use has become a key component of group activities to the extent that young people can feel left out if friends become owners before they do. Indeed, one of the main reasons given for the purchase of first mobiles is 'because everyone else had them'. Yasmin, the last person in her friendship group to get a mobile, described how she missed out on receiving group information and gossip because she didn't have a mobile phone:

Yasmin: $\quad$ Yeah, like I was one of the last ones to get my phone out of my friends and they were all, 'did you get that text, did you get that text', and I was like 'no I don't have a phone'... but like now I've got it they can send me them.

In spite of what appear to be uniformly high adoption rates and levels of use amongst young people, we also need to interrogate the assumed popularity of 'perpetual contact'. Although the vast majority of participants in our study chose to remain continually networked via their mobiles, a small minority were resisters, viewing perpetual contact as undesirable, an intrusion of private space and time. Strategies to avoid contact included not answering, leaving mobiles at home or being economical with the truth, for example, pretending to be out of battery.

Nazir: I'd rather like switch it off most times like. Sometimes I just can't be arsed to talk to nobody, my phone's ringing... and then you're like 'Hello'... and then you stop talking to him and then... five minutes later it fucking rings again... When you've got a mobile it's like you can't relax and chill, you feel... as soon as... someone calls you, you have to go and do something.

Avoiding phone calls did, however, lead to censure from peers. Saleem describes being chastised by friends for leaving his mobile at home. His absence from the network frustrates other network users.

Saleem: $\quad$ Then they give you a bollocking for [leaving it at home], like 'I've been trying to get hold of you'. 
This suggests that remaining in regular contact is an essential component of this particular peer group's culture. Entering into a network facilitated by mobile technologies leads to social expectations from others that you will be always available and on hand, with peers holding each other accountable and answerable to one another for non-availability or absence from the network.

\section{The gendered and cultural dimensions of talk and text}

Although talking and texting were popular with all, we found clear gender and cultural differences in terms of their social interactions and conversational preferences both between the participants' groups and in contrast with other youth groups. This builds upon an established body of research on gendered talk (Spender 1980; Gilligan 1982; Coates 1996) and contributes to the emerging body of work which explores the ways in which gendered talk is inscribed by / becomes inscribed in mobile phone communications. Previous research on the telephone highlighted gender differences by focusing upon masculine resistances to family telephone talk (Frissen 1995; Lohan 2001). Our findings suggest that although most of the young men are now sophisticated mobile users, 'mobile talk' remains a complex gendered phenomenon. The majority of men in our study talked about making short phone calls or texting to make arrangements with or locate male friends. They felt little need to call male friends for a long chat, explaining that face-to-face communication was preferable. More interestingly, they reported that phone calls and text messaging to girlfriends or female friends required more time as the following demonstrates:

Tahir: I think...men...just ring each other to see where you are. 
Irfan: Obviously if you're writing [texting] to your girlfriend...then you tend to spend more time on the phone.

Tahir: $\quad$ Lasses use it more to gossip or you know ring each other for a natter... whereas the lad's maybe, and the men's is strictly business, 'right what you doing'?

This quote also demonstrates how women's longer conversations are regarded by the men as 'gossip' rather than having substantive content. In contrast, the men view themselves as getting 'straight to the point'. Many of the men and some of the women also discussed how texting could help them to communicate with new girlfriends and boyfriends. Texting is of course cheaper but it also allows more of a distance when communicating emotions or feelings than voice contact, appearing to insert a layer of protection from the embarrassment of romantic conversations or potential loss of face associated with the rejection of romantic overtures, as the following sequence suggests:

Jameel: $\quad$ When you're texting girls... you send 'em something you know... and then... you're waiting then, thinking 'what, she must be writing now'. (laughs)

Khaliq: $\quad$ With texting you feel more free, you know cos you're not [actually] saying it like, on the phone are yer so you can't really feel what that person's reacting like. You just write it down don't yer and send it and then expect [anticipate] what the other person's got to say man. So its fun in a way.

Abbas: $\quad$ Plus its sorta cheaper innit cos you're saying like five, six sentences at once like, for twelve pence.

This sequence also suggests that they enjoy the fun of flirtatious texting to girls, including the excitement of waiting for an answer. Related to this, the texting interface may also encourage some to communicate in a more daring or bold manner in their sexual and romantic relations. Women participant's narratives tended to reinforce the men's comments about them by indicating their preferences for 'nattering' and 'chatting'. They agreed that they spend longer talking to female friends, particularly at 
night to catch up on 'the gossip', echoing existing work with other ethnic and age groups on 'gender talk', mobiles and the telephone (Lohan 2001; Lemish and Cohen 2005). The excerpt of dialogue below illustrates a group of young women discussing the text messages that they forward to each other. Although chain messaging is popular amongst both young women and men, the content of the messages is often gender specific. The young women in our sample sent messages to invoke and reciprocate their feelings about friendship and intimacy, a finding that reflects earlier work on the important emotional work achieved by 'women's talk' (Coates 1996; Green 1998) in maintaining female friendships.

Nina: Just like a little poem isn't it. It's just a bit of fun really. Saira: $\quad$ It's quite girly I think, I don't think boys would send them. Interviewer: What kind of things do they have in them? Yasmin: $\quad$ Its like forever friends kind of thing, I dunno I've got some on my phone.

Indeed it could be argued that these young women are either fulfilling or 'rehearsing' for their key roles in maintaining family harmony and stability (Hoschild 1989), through affirming family affections and kinship ties via technologies such as telephones and increasingly mobiles.

Since all of our participants are bi- or multi-lingual, text and talk is also conveyed by many through a mixture of languages, symbols and signs (for example, emoticons). Language is creatively blended to make the message salient, potent and often humorous. One of the young women's groups talked about phonetic techniques such as texting Punjabi words in Roman characters. Celebration text messages were also sent on important faith occasions such as $\mathrm{Eid}^{\mathrm{v}}$, combining pictures and religious texts in different languages. Mixing languages signals diverse group identities, meaning and significance, as well as highlighting the shared narratives and histories of the group and the traditions 
and cultures in which they are situated (Ling 2004). Many young people are drawn together around a broad 'configuration of values' which undergo continual transformation and permutation, through internal and external, local and global influences (Nayak 2003). Indeed, we would argue that mobile phone communication enables a complex display and articulation of multi-faceted identities, for example, Asian British, as the following group discussion shows:

Interviewer: And do you mix language?

Tahir: $\quad$ Yeah you do sometimes, yeah like [Punjabi word].

Interviewer: What does that mean?

Irfan: It means Asian for 'fuck off'.

(Group laughter)

Tahir: No, I think if you've got friends that speak [the same language]...like we have British-Asian [friends] so...our Asian friends will be able to speak English...or speak Punjabi...

Naeem: $\quad$ So we can use it to our advantage, ya know... say there's all Asians around.

Tahir: $\quad$ If I want to text him and I think it sounds funnier... I'll text in my own language.

Group dialogue and language can be both inclusive and exclusive, used to strengthen the social glue between peers but also to exclude others, depending on context. Three of the groups discussed conversing in Punjabi amongst non-Punjabi speakers when a degree of conversational privacy was required. Tahir illustrated this saying,

Like if there's loads of non-Asians and I only want him to understand, I will say it in my own language, and then only he'll understand it.

A particularly appealing aspect of the mobile phone then is its capacity to create and enhance private, flexible spaces that can be appropriated by peer groups of young people. For these young people, bi-lingual conversations and texts represent translated and transformed cultural identities, where different traditions, narratives, dialogues and references are fused to create new and diverse group identities. Participants borrow and rework a wide variety of accents, phrases and dialects, the result of which is a melting 
pot of conversational and written, gendered and cultural styles where meanings are coded and sometimes restricted to insiders. In one men's group they described 'street' talk as their lingua franca, a language drawn from a range of influences and developed to (re)present the image of their friendship group:

Interviewer: So what kinda language d'you use on the phone, English? Waseem: Punjabi.

Adil: $\quad$ I make up my own.

Jameel: $\quad$ All sorts like street language, different accents... We're usually using like... street slang and stuff like that... instead of me saying 'oh thanks', we really say safe. Like that, you getting me, we still paying respect but it's our way of respect man...

The concept of 'diasporic space' is useful here as a critique of theories that point to a globalised and homogeneous youth culture (Qureshi and Moores, 2001: 314). This approach emphasises the importance of exploring localised and situated differences and complexities which result from cultural convergences. As our research shows, a local youth culture can draw upon a range of local and global influences and differ according to degrees of economic power, fashions and peer group habits. Such an approach importantly recognises that whilst different young people may come together around commonalities such as the ownership of mobile phones, the diverse ways in which those mobiles are used / not used, personalised and adapted, yield rich insights into the heterogeneity, spatiality and temporality of youth cultures and identifications.

\section{Mobile identity projects}

Mobiles offer space in which identities can be constructed, presented and stored; use of mobiles shapes aspects of who we are, where we go and what we do. The personalisation of mobiles has led to suggestions that they can be seen as extensions or parts of the body 
and self. Oksman and Rautiainen's (2003) research on Finnish teens show how mobiles are perceived as living organisms connected to the self. Indeed when asked if they could live without mobiles some of our participants likened giving up their mobiles to a severance of part of themselves. Other research has pointed to gender-related styles of mobile phones (Skog, 2002) but our research suggests that whilst mobiles can reflect gendered presentations of the self, the intersection of gender identities with different cultural and peer group styles results in less rigid and homogeneous gender distinctions. Many of our participants exhibited a keen interest in having the latest phones and styles and regularly took out their mobiles in focus group sessions to show the researcher and other participants. They discussed at length the aesthetics of mobiles in terms of models, styles, functions, contracts, and networks (Ling 2004). During the period of fieldwork, both men and women agreed that slim, small, often silver phones were 'in' and 'bricks', that is larger, more dated models, were 'out'. It appears that the current desire for sleek, silver phones by both men and women cuts across gender preferences and associations between technology and masculinity, but the personalisation of such phones is definitely gendered.

Style says something about social identity and status, with peers sharing similar tastes in phones, which is also linked to their financial capability. Although the mobile does not have the same social status that it had in the early 1990s (Mortberg 2003), our research discovered that ownership of different models and capabilities earned young people different levels of social, cultural and socio-technical status and capital, depending on context. This group discussed the negative connotations associated with cheaper, 'old fashioned' phones and commented on the status achieved by owning a D500 phone:

Abbas: $\quad$ If you've got a big phone now they're gonna say, 'oh look at him, he's cheap and he's nasty yeah', cos big phones cost less don't they cos they're 
bricks and small ones they're the new ones nowadays. Plus they look better man when they're small.

Jameel: $\quad$ Yeah there's loads of big people out there thinking they're all that with their, you know, D500's and that.

As Naeem's comment below illustrates, many of the men were concerned with projecting a 'cool', stylish, techno-savvy, masculine image where phones become symbolic tools which complement the gendered and cultural presentation of the self and the peer group:

I think when you look at somebody and their clothes... I think phones have become part of that, its part of their personality, when you look at them you look at their phone as well.

Girls tended to observe that the men in their families were more interested in new types of phones than they were. Although many of the women discussed the capabilities and aesthetics of the latest mobiles very knowledgeably, most showed less interest in their ownership. In this particular female group identity projects rely less on technological hardware and more on other consumer items such as fashionable clothing and footwear:

Interviewer: So, do you all update them on a regular basis?

Sugra: $\quad$ No.

Robina: $\quad$ People I know do, not myself...

Sugra: $\quad$ Yeah, people are known to, I don't know whether I can be seen around with my phone. I'm not really bothered about what I've got because... there's a new one nearly every three weeks or something like that.

Naira: $\quad$ You can't keep up with it, you can't keep up.

Sugra: $\quad$ No way, I think it's more important for the boys cos... it's more important keeping up, whereas with girls it's just like personally which mobile do you like the most, not really bothered about...

Shamila: $\quad$ About the style

Robina: I'd rather spend my money on what I want

Shamila: Clothes and shoes. (Laughing)

Indeed, the young mother's group also agreed that money was better spent elsewhere, for example on their families, although they indicated that their husbands owned the latest phones. It may also be that as long as the couple or family owned the latest phone, the 
women didn't need to have one of their own, since a major part of their identity was as wives and mothers. This reminds us that a variety of subject positions exist in people's everyday lives and a person positions her / himself in, and is placed in, positions which afford different statuses, rights and obligations. Multiple positions co-exist, which means that identities are shaped in tensions between those various positions and are neither uniform nor fixed but fragmented and fluid (Hollway 1984; Woodward 1997).

\section{Exploring subjectivities: mosaics of identity}

New phone technologies enable the young women and men to extend their participation in more localised and global social networks and to explore new ways of personalising and identifying with their phones. Our data contains references to multi-faceted cultural and gender identities, including a consensual 'Asian' identity amongst both young females and males that intersects with wife and mother categories for some of the women. Group discussions revealed that exploring the personalisation processes that surround individual mobiles uncovers multiple and diverse aspects of personal identity, sometimes in tension with one another, which are useful in grounding the concept of intersectionality. Razvanah's narrative gives us a glimpse of how the personalisation and carrying of her mobile phone illustrates the complexity, and sometimes tension, of the intersection between her key identity as a wife and mother and her status as a young woman interested in fashion. She begins by saying that she doesn't have time to use or 'play' on her mobile like some of the other women in the group:

I've got a twelve week old baby and you just don't get a chance [to use it]. Once I've finished with him, I've got my husband off to work, it's ... twelve o'clock then you do the housework and I've gotta sort [myself out] as well... you don't have time to play around on your phone. 
Moments later in discussion with Shabnam she comments that she wants to upgrade her phone and at the end of the sequence refers to the importance of having a mobile as a 'fashion accessory'. Razvanah's 'fashion accessory' is also a repository for pictures of her baby and contact point for her husband, reflecting the different aspects of her own identity. Shabnam on the other hand suggests that there is little point purchasing a new mobile because she doesn't use it frequently illustrating the ways in which the women share some common experiences of technology but diverge on others:

Razvanah: I'm gonna get [a new camera phone], you know them square ones. I'm gonna get one of them.

Shabnam: I'm gonna stick with the old one cos ma husband's always saying get a new one and I go 'what's the point', I only have it in my pocket.

Razvanah: But with me it's a fashion accessory... It's just for my husband and stuff, for him to keep in touch with me, I don't ring him (laughs). But with me it's more of a fashion accessory. Now that I've got a baby I [put] photos of him on ma phone.

Young people draw upon a range of cultural repertoires to personalise their phones, and these are continuously subject to adaptation and change. Participants' phones had the latest Asian ringtones, including Bhangra and Bollywood love songs and also R\&B, alternative music and mainstream pop tunes, downloaded from websites or recorded from various media sources. Their choices of wallpapers, screensavers and phone covers also reveal gendered, cultural identities with women tending to favour family and friendship images, including their children (for the mother's group), memorable places or their favourite celebrities, for example, Bollywood actors. Some of the men had family pictures but others decorated their phones with symbols associated with particular masculine identities, for example, pictures of naked women.

Although the participants share some cultural identifications and displays, these configurations can also differ within and between groups, and are related to gender, age 
and socio-economic position. The following dialogue foregrounds a group of young men discussing street tensions between themselves and other male groups, including style and status differences symbolised by the wearing of phone straps. What is interesting here is the way in which these young men chose to distance themselves from other strap-wearing individuals / groups and the associations of wealth that straps evoked:

Khaliq: $\quad$ I don't know if it's an Asian fashion now, they have like straps on their hand, nearly everyone's got em on man...

Abbas: $\quad$ Where we live, they haven't got like [straps]... All these rich kids live in [place name] and [street name]. They've got cars... and like the way that they act and the way we act is totally different man... If we walking down town... and we look they've got all like phone straps and stuff like that and the way they're walking and talking... They want us to be like them but it isn't working like that and they don't wanna be like us either, you know what I mean.

Khaliq: $\quad$ Go our own way isn't it, stick together.

Jameel: $\quad$ Yeah stick together man.

Our data confirms the thesis that mobiles are not neutral objects, but embody and articulate social and cultural relations. Gender relations are inscribed in objects and artefacts, both in design and appropriation and can contribute to the maintenance of gendered relations (Oudshoorn et al., 2002). Indeed, mobiles can be viewed both as gendered artefacts and also as spaces which are open to certain processes of individualisation or personalisation. Such processes are constituted by and reflective of gender norms, but are also intersected by social and cultural location and positioning thereby enabling diverse reconfigurations of identity and self-presentation.

\section{Conclusion}

In this paper we have examined the concept of shifting gendered, ethnic and cultural identities and social practices formed and re-worked in relation to mobile phones. We 
have also analysed how the use and meanings of mobiles and the performance of diverse youth identities such as British Asian, and young mother, mutually shape one another in everyday life. Our data confirms that although participants share some common aspects of identity between and across gendered youth cultures, they come from diverse backgrounds and are engaged in complex, fluid lifestyles which raise important debates about, for example, 'youth', 'gender' and technology, as descriptive and conceptual categories. Adopting a critical approach which emphasises the intersections of aspects of identity, we argue that analysis of 'difference' is crucial to gaining a broader, more heterogeneous understanding of our 'mobile selves': that is how different groups of young women and men embrace, negotiate, modify and resist technologies and practices and how these shape their individual and collective identities. The relative newness of mobile phone technology puts us in an exceptional position for witnessing its adoption, rejection, uptake and appropriation: the spectrum of reactions towards and relationships with mobiles, says something about who we are and what we do; about our identities and routine social practices. Findings from our research suggest that appropriation and use of mobile phones is intersected by gender, ethnicity and social positioning and that mobiles are key props in the production of young people's identity projects.

\section{WORD COUNT: 8,000}




\section{References}

Alexander, C. (1996) The Art of Being Black: The Creation of Black British Youth Identities, Oxford: Oxford University Press.

Back, L. (1996) New Ethnicities and Urban Culture: Racisms and Multiculture in Young Lives, London: Routledge.

Brah, A. (1996) Cartographies of Diaspora: Contesting Identities, London: Routledge. Brah, A. \& Phoenix, A. (2004) 'Ain't I A Woman? Revisiting Intersectionality', Journal of International Women's Studies 5(3):75-86.

Coates, J. (1996) Women Talk, Oxford: Blackwell.

Faulkner, W. (2001) 'The Technology Question in Feminism: A View from Feminist

Technology Studies', Women's Studies International Forum 24(1):79-95.

Frissen, V. (1995) 'Gender is calling: Some reflections on past, present and future uses of the telephone', in K. Grint and K. Gill (eds.) The Gender-technology Relation:

Contemporary Theory and Research, London: Taylor and Francis, pp. 79-94.

Gibbs, A. (1997) 'Focus Groups', Social Research Update 19 (online) Available HTTP http://www.soc.surrey.ac.uk/sru/SRU19.html (13 June 2006).

Gilligan, C. (1982) In a Different Voice, Cambridge, Mass: Harvard University Press.

Green, E. (1998) “Women Doing Friendship': An Analysis of Women's Leisure as a site of identity construction, empowerment and resistance', Leisure Studies 17:171-185.

Green, E. \& Adam, A. (eds.) (2001) Virtual Gender: Technology, Consumption and Identity, London: Routledge.

Green, N. (2003) 'Outwardly Mobile: Young People and Mobile Technologies' in J. E. Katz (ed.) Machines that become us: The Social Context of Personal Communication Technology, London: Transaction, pp. 201-217.

Hall, S. (1996) 'Introduction: Who Needs 'Identity'?' in S. Hall \& P. du Gay (eds.) Questions of Cultural Identity, London: Sage, pp. 1-17.

Harper, R. (2003) ‘Are Mobiles Good or Bad for Society?' in K. Nyíri (ed.) Mobile Democracy: Essays on Society, Self and Politics, Vienna: Passagen Verlag, pp. 185-213. Hollway, W. (1984) 'Gender Difference and the Production of Subjectivity', in J. Henriques, W. Hollway, C. Urwin, C. Venn \& V. Walkerdine (Eds.) Changing the Subject: Psychology, Social Regulation and Subjectivity, London: Methuen, pp. 227-263. Hoschild, A. R. (1989) The Second Shift, Berkley: University of California Press. Katz, J. E. \& Aakhus, M. (2002) 'Introduction: framing the issues', in J. E. Katz \& M. Aakhus (Eds.) Perpetual Contact: Mobile Communication, Private Talk, Public Performance, Cambridge: Cambridge University Press, pp. 1-14.

Kennedy, H. (2005) 'Subjective Intersections in the Face of the Machine: Gender, Race, Class and PCs in the Home', European Journal of Women's Studies 12(4):471-487.

Lemish, D. \& Cohen, A. A. (2005) 'On the Gendered Nature of Mobile Phone Culture in Israel', Sex Roles 52 (7/8):511-521.

Ling, R. (2000) "We will be reached": the Use of Mobile Telephony among Norwegian

Youth', Information, Technology and People 13(2):102-120.

Ling, R. (2004) The Mobile Connection: The Cell Phone's Impact on Society, San

Francisco: Elsevier.

Lohan, M. (2001) 'Men, Masculinities and 'Mundane' Technologies: The Domestic

Telephone' in E. Green \& A. Adam (Eds.) Virtual Gender: Technology, Consumption and Identity, London: Routledge, pp. 189-205.

Mortberg, C. (2003) 'Heterogeneous images of (mobile) technologies and services: A feminist contribution', Nordic Journal of Women's Studies 11(3):158-169. 
Moyal, A. (1992) 'The Gendered Use of the Telephone: an Australian Case Study', Media, Culture and Society 14:51-72.

Nayak, A. (2003) Race, Place and Globalization: Youth Cultures in a Changing World, Oxford: Berg.

Oksman, V. \& Rautiainen, P. (2003) "“Perhaps it is a Body Part": How the Mobile Phone became an Organic Part of the Everyday Lives of Finnish Children and Teenagers' in J.

E. Katz (Ed.) Machines that become us: The Social Context of Personal Communication

Technology, London: Transaction, pp. 293-308.

Office for National Statistics (2003) 'Adult mobile phone ownership: by age, 2001 and 2003' (Online) Available HTTP

http://www.statistics.gov.uk/StatBase/Expodata/Spreadsheets/D7202.xls. (27th January 2005)

Oudshoorn, N., Saetnan, A. R. \& Lie, M. (2002) 'On Gender and Things: Reflections on an Exhibition on Gendered Artefacts', Women's Studies International Forum 25(4):471483.

Qureshi, K. \& Moores, S. (1999) 'Identity Remix: Tradition and Translation in the Lives of Young Pakistani Scots', European Journal of Cultural Studies 2(3):311-330.

Rakow, L. (1988) 'Women and the Telephone: the Gendering of a Communication Technology', in C. Kramarae, (Ed.) Technology and Women's Voices: Keeping in Touch, New York: Routledge, pp. 207-228.

Rakow, L. \& Navarro, V. (1993) 'Remote Mothering and the Parallel Shift: Women meet the Cellular Phone', Critical Studies in Mass Communication 10(2):144-157.

Silverstone, R. \& Haddon, L. (1996) 'Design and the Domestication of Information and Communication Technologies: Technical Change and Everyday Life' in R. Mansell \& R. Silverstone (Eds.) Communication by Design: the Politics of ICTs, Oxford: Oxford University Press, pp. 44-74.

Skog, B. (2002) 'Mobiles and the Norwegian Teen: Identity, Gender and Class', in J. E. Katz \& M. Aakhus (Eds.) Perpetual Contact: Mobile Communication, Private Talk, Public Performance, Cambridge: Cambridge University Press, pp. 255-273.

Spender, D. (1980) Man Made Language, London: Routledge and Kegan Paul.

Terry, J. \& Calvert, M. (1997) 'Introduction' in J. Terry \& M. Calvert (Eds.) Processed

Lives: Gender and Technology in Everyday Life, London: Routledge, pp. 1-19.

Urry, J. (2000) Sociology beyond Societies: Mobilities for the twenty-first century, London: Routledge.

Wajcman, J. (2004) TechnoFeminism, Cambridge: Polity Press.

Woodward, K. (1997) 'Concepts of Identity and Difference', in K. Woodward (Ed.) Identity and Difference, London: Sage, pp. 8-50.

\footnotetext{
${ }^{\mathrm{i}}$ The exchange of material gifts through digital media (Johnsen 2003).

${ }^{\text {ii }}$ One participant was an Arab-British Muslim man and was involved in the focus group through friendship with the other men.

iii In defining 'race' and ethnicity we espouse the view that 'race' has no legitimate base in science and is socially constructed (Brah 1996) although is often represented in everyday life as a fixed and objective category of identity, where definitions of 'race' often employ signifiers, for example, skin colour or country of origin which are mobilised to marginalise different social groups. Ethnicity, like 'race' signifies a process and is relational but is primarily a mechanism of 'boundary maintenance' between groups (Brah 1996). 'Race' and ethnicity are not isolated from other social categories and are continuously [re] produced with other forms of difference across social settings.

${ }^{\text {iv }}$ Male and female mobile users met in separate groups for cultural and faith reasons, a choice advised by community assistants.
} 
${ }^{\mathrm{v}}$ Eid is a Muslim festival. There are two Eid festivals in the year: one to celebrate the end of Ramadan, the month of fasting; and the other to celebrate the end of Hajj, the pilgrimage to Mecca. 